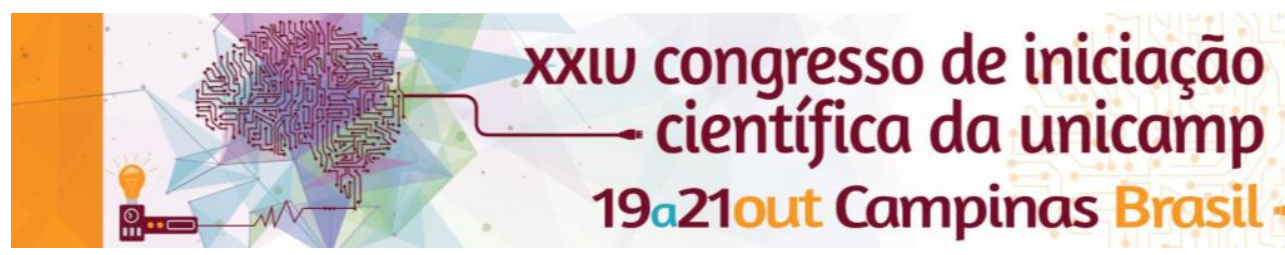

\title{
Torrefação da Biomassa Cana Energia Saccharum sp IACSP95-5000 para a Geração de Biocombustível Sólido
}

\author{
Raissa Coelho de Carvalho*, Henrique Real Guimarães, Katia Tannous
}

\section{Resumo}

Este trabalho tem por objetivo avaliar o processo de torrefação da cana-de-açúcar IACSP95-5000 para a produção de biocombustível sólido. A decomposição térmica foi avaliada mediante termogravimetria a fim de obtenção das variáveis (temperatura e tempo) para os ensaios isotérmicos da torrefação em mufla. As condições brandas (200 ${ }^{\circ} \mathrm{C}$ e $40 \mathrm{~min}$ ) foram selecionadas a fim de obter perdas mássicas inferiores a $30 \%$ e rendimento energético superior a $90 \%$.

\section{Palavras-chave}

Biomassa, torrefação, cana-de-açúcar

\section{Introdução}

A biomassa é um recurso alternativo aos combustíveis fósseis, porém in natura é caracterizada pela alta umidade, comportamento higroscópico, maior volume e baixa densidade energética, dificultando seu armazenamento. Assim, tratamentos prévios são necessários a fim de tornar a biomassa um combustível competitivo, seja sólido, líquido ou gasoso. Com isso, o objetivo desse trabalho fol avaliar as condições experimentais de torrefação isotermicamente para a cana-de-açúcar IACSP95-5000.

\section{Resultados e Discussão}

Através da decomposição térmica (Figura 1) da amostra $\left(25-900^{\circ} \mathrm{C}\right)$ de diâmetro médio entre peneiras de $251,5 \mu \mathrm{m}$ definiram-se as variáveis da torrefação realizadas em mufla. A TG apresentou faixas específicas referente a decomposição dos açúcares, hemicelulose, celulose e lignina.

Figura 1 - TG e DTG normatizadas da IACSP95-5000 ( $\left.\beta=20^{\circ} \mathrm{C} / \mathrm{min}\right)$

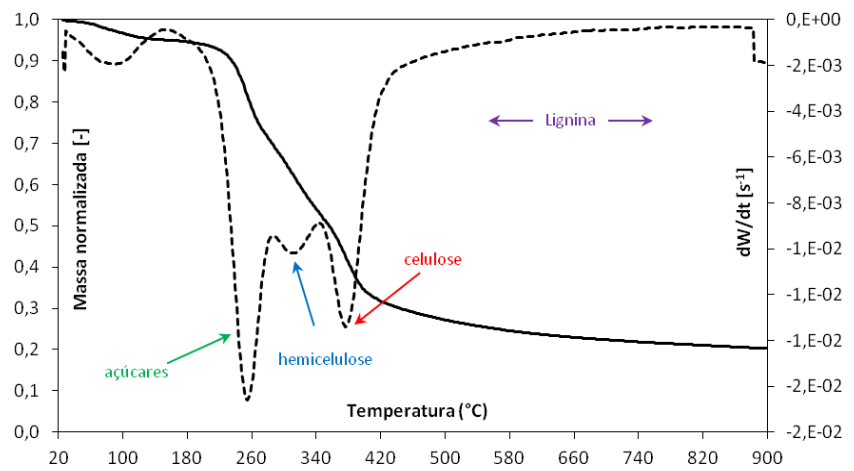

Um planejamento experimental (Tabela 1) do tipo $2^{2} \mathrm{com}$ repetição no ponto central foi realizado a fim de obter um ponto ótimo de operação na torrefação. O rendimento mássico (RM), Equação 1, representa a massa remanescente da amostra após a torrefação e o rendimento energético (RE), Equação 2, avalia a energia retida no material.

Tabela 1. Planejamento experimental e resultados da biomassa

\begin{tabular}{|c|c|c|c|c|c|}
\hline $\mathrm{T}\left({ }^{\circ} \mathrm{C}\right)$ & $\mathrm{T}(\mathrm{min})$ & $\mathrm{RM}(\%)$ & \multicolumn{2}{|c|}{$\mathrm{PCS}(\mathrm{MJ} / \mathrm{kg})$} & $\mathrm{RE}(\%)$ \\
\hline & & & in natura & Torrificada & \\
\hline 200 & 10 & 88,34 & \multirow{5}{*}{16,24} & 17,2 & 93,53 \\
\hline 200 & 40 & 76,62 & & 19,36 & 91,35 \\
\hline 235 & 25 & 63,31 & & 20,77 & 80,95 \\
\hline 260 & 10 & 65,27 & & 20,58 & 82,62 \\
\hline 260 & 40 & 49,41 & & 22,37 & 68,96 \\
\hline
\end{tabular}

$\mathrm{RM}=\mathrm{M}_{\text {tor }} / \mathrm{M}_{\mathrm{i}} \quad$ (1) $\quad \mathrm{RE}=\left(\mathrm{M}_{\text {tor }}{ }^{*} \mathrm{PCS} \mathrm{S}_{\text {tor }}\right) /\left(\mathrm{M}_{\mathrm{i}}^{*} \mathrm{PCS} \mathrm{S}_{\mathrm{i}}\right)$

De uma maneira geral, o aumento da severidade (tempo e temperatura) provocou um maior aumento do poder calorífico, embora acompanhado de um menor RE associado a uma maior perda de massa (menor RM), conforme pode ser visto na Figura 2.

Figura 2- Amostras nas diferentes condições de torrefação

\begin{tabular}{|c|c|c|c|}
\hline $\mathrm{T} / \mathrm{t}$ & $10 \mathrm{~min}$ & $25 \mathrm{~min}$ & $40 \mathrm{~min}$ \\
\hline $200^{\circ} \mathrm{C}$ & & - & \\
\hline $230^{\circ} \mathrm{C}$ & - & & - \\
\hline $260^{\circ} \mathrm{C}$ & & & \\
\hline
\end{tabular}

O poder calorífico teve um aumento em relação à biomassa in natura dividido em três situações: $6 \%$ para condições mais brandas, entre 19 e $28 \%$ para condições intermediárias e $40 \%$ para as condições mais severas. O ponto central teve um comportamento similar ao ponto de temperatura mais severa $\left(260^{\circ} \mathrm{C}\right) \mathrm{com}$ um menor tempo de residência $(10 \mathrm{~min})$, mostrando que um maior tempo de residência compensou a diminuição na temperatura. Um rendimento energético superior a $90 \%$ foi encontrado apenas nas condições de temperatura mais brandas nos dois tempos principais estudados (10 e $40 \mathrm{~min}$ ).

\section{Conclusões}

A torrefação apresentou uma alternativa viável para favorecer a utilização da biomassa como combustível sólido, principalmente nas condições de temperaturas mais brandas $\left(200^{\circ} \mathrm{C}\right)$ e tempo de residência mais longo, (40 min). Com isso, as perdas mássicas inferiores a $30 \%$ e rendimento energético superior a $90 \%$ foram validados com a literatura.

\section{Agradecimentos}

Os autores agradecem ao CNPQ pelo apoio-financeiro e aos colegas do LaProM-FEQ pelo auxílio no projeto.

1. VAN DER STELT, M.J.C.; GERHAUSES, H.; KIEL, J.H.A; PTASINSKI, K.J. Biomass upgrading by torrefaction for the production of biofuels: A review. Biomass and Bioenergy, v.35, p. 374-762, 2011

2. FELFLI, F. E. F. Melhoramento das características energéticas de resíduos de biomassa através da torrefação. Dissertação de Mestrado em Engenharia Mecânica. Universidade Estadual de Campinas, Campinas, 1999. 